\title{
Effect of the molecular weight of polyvinylpyrrolidone on the structure and morphology of materials based on substituted hydroxyapatite for bone implants
}

\author{
Elizaveta A. Mukhanova ${ }^{1,2^{*}}$, Inna A. Suprunova ${ }^{1}$, Yana A. Suprunova ${ }^{1}$, Igor Yu. Zabiyaka ${ }^{2}$ \\ ${ }^{1}$ Southern Federal University, 344006 Rostov-on-Don Bolshaya Sadovaya str. 105/42, Russia \\ ${ }^{2}$ Don State Technical University, 344000 Rostov-on-Don pl. Gagarina 1, Russia
}

\begin{abstract}
In this work, we study the influence of various molecular weights of polyvinylpyrrolidone (PVP) on synthesis substituted hydroxyapatite. Using the scanning electron microscopy we estimated the size and morphology of the particle. We studied the structural transformations of phosphates and the effect of polymer sizes on the structure and morphology. We revealed the thermodynamic stability of the structure of hydroxyapatite due to experimental results.
\end{abstract}

\section{Introduction}

The morphology of bioactive ceramics significant effects on its properties (mechanical, chemical and so on) [1-5]. Changes in synthesis conditions influence on size and shape of crystals [6-9]. One of the routes to change synthesis represents by using the polymer as templates before high-temperature annealing. In our work, we studied the effect of PVP addition. This polymer is non-toxic and soluble in water and many organic solvents, a poreformer agent in membrane fabrication for biomedical applications, water purification, wastewater treatment, desalination, food processing (e.g., beer and wine filtration), gas separation and so on [10]. The research of PVP for present and future applications as a medical or nonmedical biomaterial that can bring significant improvement to our everyday life has the high potential. But the most research works described PVP with low molecular weight [11-15].

The aim of our work is to study have a molecular weight of PVP any effect on the morphology of the synthetic bioactive ceramic with composition $\mathrm{Ca}_{9} \mathrm{Y}\left(\mathrm{PO}_{4}\right)_{5} \mathrm{SiO}_{4}(\mathrm{OH})_{2}$. For this purpose, we choose PVP with four different molecular weight.

\section{Materials and methods of research}

\subsection{Preparation of $Y$, Si-substituted hydroxyapatite with different porosity}

$\mathrm{Ca}_{9} \mathrm{Y}\left(\mathrm{PO}_{4}\right)_{5} \mathrm{SiO}_{4}(\mathrm{OH})_{2}$ was synthesized by sol-gel method using $\left.\mathrm{CaO}, \mathrm{Y}_{\left(\mathrm{NO}_{3}\right.}\right)_{3} \bullet 6 \mathrm{H}_{2} \mathrm{O}$, TEOS and $2.1 \mathrm{M} \mathrm{H}_{3} \mathrm{PO}_{4}$ as initial substances. $\mathrm{CaO}$ was soluted in cold distilled water

\footnotetext{
*Corresponding author: kand@sfedu.ru
} 
obtaining $0.6 \mathrm{M} \mathrm{Ca}(\mathrm{OH})_{2}$. This solution was mixed with yttrium nitrate solution and stirring for 1 hour. Then we added TEOS and $\mathrm{H}_{3} \mathrm{PO} 4$ while stirring and ammonium hydroxide solution to hold $\mathrm{pH}$ at 10-11. The mixture was left overnight to stir and after we add PVP with different molecular weight as a template to 4 samples. Basic properties of PVP are presented in Table 1. The solution stirred for 3 days and then filtrated and heated at $120^{\circ}$ for 12 hours. The dry precipitations heated in furnace subsequently at $400,600,900$ and $1100{ }^{\circ} \mathrm{C}$.

Table 1. Molecular weight of different PVP samples

\begin{tabular}{|c|c|c|}
\hline № & Sample name & Molecular weight \\
\hline 1 & PVP V200 & $6.4-6.7 \cdot 10^{4}$ \\
\hline 2 & PVP V500 & $1.3-1.9 \cdot 10^{5}$ \\
\hline 3 & PVP V1000 & $2.2-2.3 \cdot 10^{5}$ \\
\hline 4 & Polidon & $1.8-2.1 \cdot 10^{6}$ \\
\hline
\end{tabular}

\subsection{Characterization Techniques}

X-ray diffraction (XRD) is carried out for phase identification using ARL X'TRA diffractometer with $\mathrm{CuK} \alpha(\lambda=1.5406 \AA)$ radiation. The XRD peaks are recorded in $2 \theta$ range of $5-70^{\circ}$. The surface morphology and microstructure of the samples before and after incubation in SBF was investigated by Scanning Electron Microscopy with ZEISS CrossBeam-340.

\section{Results and discussion}

The XRD patterns of all samples are shown in Fig. 1(a-d). The main phase in the samples with Polidon and V1000 after $900{ }^{\circ} \mathrm{C}$ treatment is hydroxyapatite (Fig. $1 \mathrm{c}-\mathrm{d}$ ). The peaks of phase with Polidon as template are wider and lower. We can suggest that this sample has a lower crystallinity. The sample with V500 after $900^{\circ}$ has additional lines of $\mathrm{YPO}_{4}$, after $1050^{\circ} \mathrm{C}$ only lines of hydroxyapatite-like phase. The crystallinity of this sample is higher. In the sample with V200 the rate of the reaction is lower and the single phase with a structure of $\beta-\mathrm{Ca}_{3}\left(\mathrm{PO}_{4}\right)_{2}$ appeared after heating at $110{ }^{\circ}$ for 3 hours (Fig. 1a). This analyses pointed out that the molecular weight of polymer affects not only the material's size and degree of crystallinity but the structure. A thermodynamical aspect of this observation requires further studies.

Fig. 2 shows the morphology of all samples after synthesis. The consideration of shape and size of Y, Si-substituted calcium phosphate shows that using PVP with low molecular weight resulted in «fused» structure with pore structure. The cylindrical crystals of doped calcium phosphate formed in the samples with a high molecular weight of the polymer. The size of crystallites changes unevenly at first sight. But the crystal structure and ability to "fusion" change too. If we consider in pair only Fig. 2 (a)-(b) and Fig. 2 (c)-(d) we can see that enlargement of polymer weight leads to decrease of size pores $(a-b)$ or crystals $(c-d)$. 


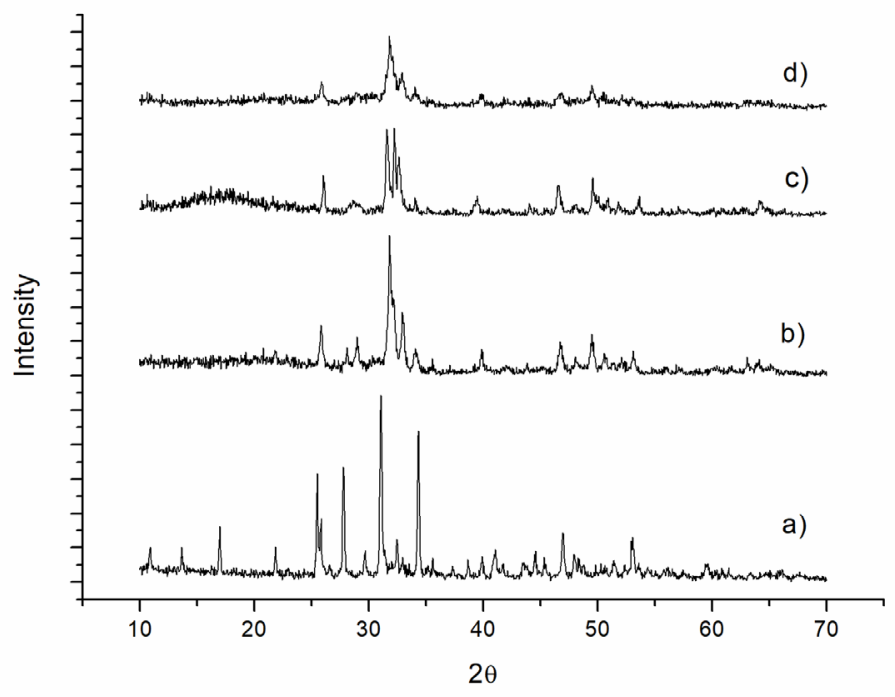

Fig. 1. XRD patterns of synthesized $\mathrm{Ca} 9 \mathrm{Y}_{(}\left(\mathrm{PO}_{4}\right)_{5} \mathrm{SiO} 4(\mathrm{OH})_{2}$ with using as template (a) PVP V200, (b) PVP V500, (c) PVP V1000 and (d) PVP Polidon.
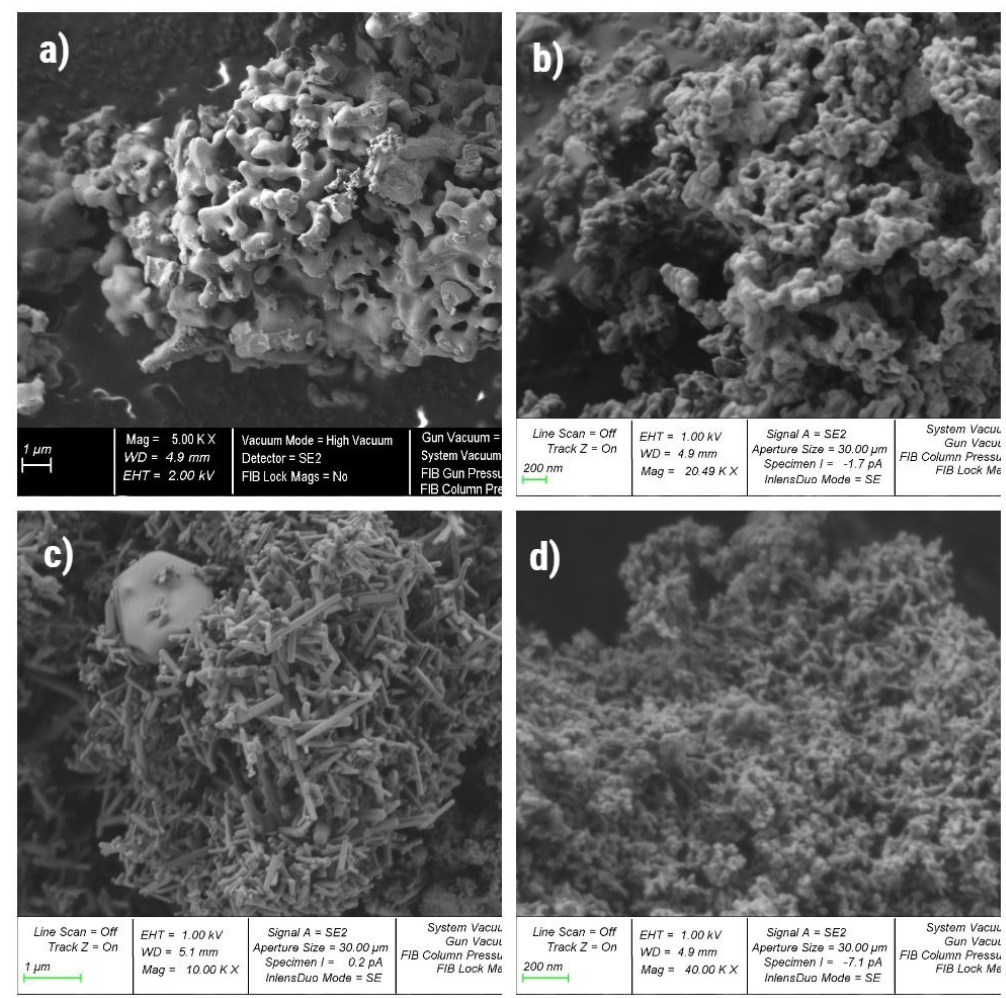

Fig. 2. SEM images of samples with using as template (a) PVP V200, (b) PVP V500, (c) PVP V1000 and (d) PVP Polidon. 


\section{Conclusion}

Both analyses pointed out that molecular weight of PVP influence on crystal size, the thermodynamical stability of structure and ability to for "fused" agglomerates. The PVP V200 leads to $\beta-\mathrm{Ca}_{3}\left(\mathrm{PO}_{4}\right)_{2}$ structure whereas in other cases hydroxyapatite is the main phase. Between PVP V500 and V1000 is a border of "fused" morphology and separate crystallinity. Within each group higher molecular weight reduces the crystal size. The results of this investigation can be used for the direct synthesis of bioactive ceramics.

This research was supported by grant of the Government of Russian Federation no. 14.Z50.31.0046.

\section{References}

1. L. Pastero, M. Bruno, V.V. Caluso, Minerals, 7, 139 (2017)

2. M. Meskinfam, M. A. S. Sadjadi, H. Jazdarreh, K. Zare, J. Biomed. Nanotechnol, 7, 455 (2011)

3. T. Leventouri, Biomaterials, 24, 4205 (2003)

4. A. Tampieri, G. Celotti, E. Landi, M. Sandri, N. Roveri, G. Falini, J Biomed Mater Res, 67, 618 (2003)

5. A. E. Porter, N. Patel, J. N. Skepper, S. M. Best, W. Bonfield, Biomaterials, 25, 3303, (2004)

6. V. Uskokovi, D. P. Uskoković, J. Biomed. Mater. Res. Part B Appl. Biomater, 96B, $152(2011)$

7. J. H. Chung, Y. K. Kim, K. H. Kim, T. Y. Kwon, S. Z. Vaezmomeni, M. Samiei, M. Aghazadeh, S. Davaran, M. Mahkam, G. Asadi, A. Akbarzadeh, Artif. Cells, Nanomedicine Biotechnol, 44, 277 (2016)

8. A. K. Nayak, Int. J. ChemTech Res, 2, 974 (2010)

9. R. Murugan, S. Ramakrishna, Biomaterials, 25, 3829 (2004)

10. M. Teodorescu, M. Bercea, Polym. - Plast. Technol. Eng., 54, 923 (2015)

11. S. Jegatheeswaran, S. Selvam, V. Sri Ramkumar, M. Sundrarajan, Mater. Sci. Eng., 67, 8 (2016)

12. B. Chaudhuri, B. Mondal, S. K. Ray, S. C. Sarkar, Colloids Surfaces B Biointerfaces, 143, 71 (2016)

13. I. S. Elashmawi, H. E. Abdel Baieth, Curr. Appl. Phys., 12, 141 (2012)

14. S. Morariu, M. Bercea, M. Teodorescu, M. Avadanei, Eur. Polym. J., 84, 313 (2016)

15. Y. Ma, T. Bai, F. Wang, Mater. Sci. Eng., 59, 948 (2016) 